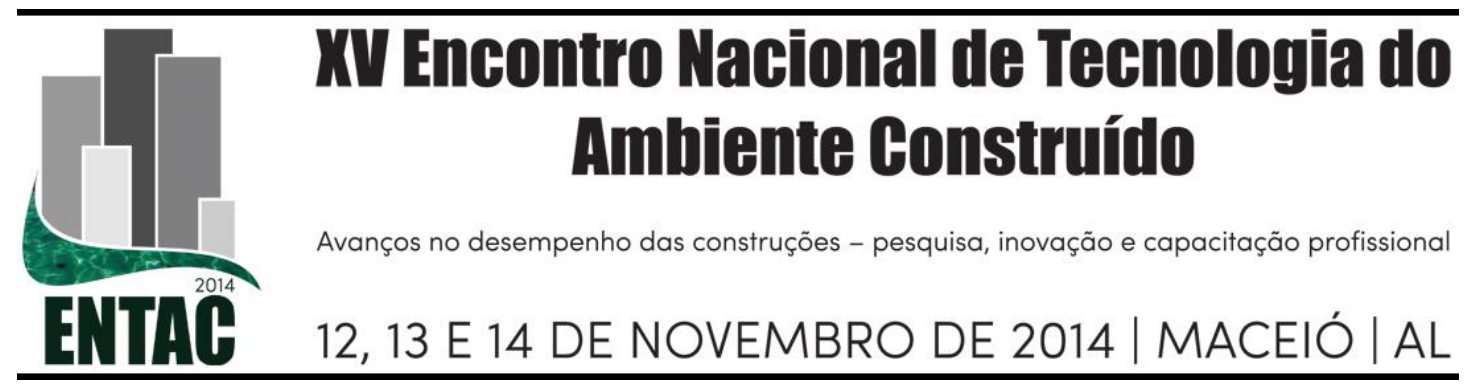

\title{
QUALIDADE NA GESTÃO DO PROCESSO DE PROJETO: AVALIAÇÃO DO GRAU DE UTILIZAÇÃO DO PROCEDIMENTO
}

\author{
FRANCO, Jéssica V. (1); PICCHI, Flávio A. (2); \\ (1) Universidade Estadual de Campinas, e-mail: j.valejofranco@gmail.com \\ (2) Universidade Estadual de Campinas, e-mail: fpicchi@lean.org.br
}

\begin{abstract}
RESUMO
No cenário atual, a Gestão da Qualidade em uma empresa Construtora já não foca somente na qualidade do produto, as empresas expandiram seu entendimento para todos seus processos, incluindo a gestão do processo de projeto. Neste contexto, este trabalho tem como objetivo avaliar o grau de utilização do procedimento de qualidade na gestão do processo de projeto, buscando identificar os pontos mais importantes e que necessitam maior atenção. Para a avaliação, foram coletados mensalmente dados de empreendimentos em uma empresa construtora. Os resultados mostraram que a análise crítica de projetos é o principal ponto de atenção na etapa de desenvolvimento de projetos e o controle de alterações de projetos é o item mais difícil de ser aplicado na gestão do processo de projeto durante as obras. O trabalho também aborda algumas características da empresa estudada que podem ter influenciado nos resultados obtidos e traz como contribuição um modelo de avaliação que pode ser aplicado em outras empresas e empreendimentos, bem como os resultados da empresa estudada que podem servir como ponto de partida para a expansão da discussão sobre o tema.
\end{abstract}

Palavras-chave: Gestão do processo de projeto, Gestão da Qualidade

\begin{abstract}
Nowadays, Quality Management in a Construction Company is no longer focused only on the Product Quality since the companies have expanded this concept to all their processes including Design Management. In this context, this paper aims at evaluating the Quality procedure's degree of use in Design Management to identify the most relevant themes which require more attention. This evaluation comprised the collection of monthly data from ongoing Projects in a Construction Company. The results showed that design review was the main concern in the Design Development phase while design changes were the most difficult item to apply during the Construction phase. This paper also approaches some of the Company particularities that may had influenced the results and, as a contribution, it brings an evaluation method that can be applied in other companies and Projects in addition to the results of the Company studied which can be used as the starting point for expanding the discussion about this theme.
\end{abstract}

Keywords: Design Management, Quality Management

\section{INTRODUÇÃO}

No cenário brasileiro atual, a gestão da qualidade dentro de uma empresa construtora deixou de focar somente a conformidade do produto abrangendo a qualidade como um sistema que inclui neste a gestão do processo de projeto.

O objetivo deste trabalho é avaliar o grau de utilização do procedimento de Gestão do Processo de Projeto na empresa construtora estudada e identificar quais tópicos do item 
7.3. da norma ISO 9001 apresentaram maior dificuldade de implementação e quais foram os problemas relacionados ao desempenho dos empreendimentos avaliados.

A metodologia utilizada consistiu em uma avaliação estruturada, com periodicidade mensal, ao longo de cinco meses consecutivos, dos empreendimentos da empresa construtora. A avaliação foi feita com base no grau de utilização dos documentos, do cumprimento do procedimento pela equipe responsável e com base na qualidade do conteúdo dos registros apresentados.

A estrutura do trabalho é dividida de forma que primeiramente foi realizado um levantamento bibliográfico a respeito do tema qualidade na gestão do processo de projeto. Em seguida, é apresentado de forma detalhada a metodologia utilizada descrevendo a estratégia de pesquisa, a forma de caracterização da empresa e dos empreendimentos avaliados, os documentos avaliados, os critérios e o processo de avaliação em si. No próximo setor, foram apresentados os resultados obtidos e a avaliação em torno destes e por último as conclusões da pesquisa e o aceno para trabalhos futuros.

\section{QUALIDADE NA GESTÃO DO PROCESSO DE PROJETO}

A preocupação com a qualidade em uma empresa Construtora já não se limita apenas ao que diz respeito à conformidade do produto final e hoje abrange todos os processos da empresa, atuando através de um sistema.

O PMI (2014) define que o gerenciamento de qualidade inclui os processos e as atividades da organização executora que determinam as políticas de qualidade, os objetivos e as responsabilidades, de modo que o empreendimento satisfaça às necessidades para as quais foi empreendido.

O projeto tem grande influencia na qualidade do produto e no sucesso de um empreendimento, de acordo com Melhado (2001), cada vez mais a forma de projetar exige alterações, pela sua capacidade de antecipar e solucionar pontos críticos para a implementação de inovações e influenciar o resultado final quanto à qualidade e custos, acompanhando as tendências verificadas na evolução dos próprios meios de produção.

De acordo com Picchi (1993) os pontos mais importantes para a garantia e controle da qualidade de projetos de edifícios são: qualificação de profissionais de projeto e de novos projetos; coordenação e análise crítica de projetos; elaboração de projetos para produção; controle da qualidade de projetos; controle de modificações durante a produção; elaboração de projetos com emprego de recursos computacionais; e parâmetros de projeto relacionados com o tempo.

No entanto, enquanto diversas pesquisas enfocam a qualidade do projeto, poucos abrangem sua gestão como ponto crítico. Em um estudo com escritórios de projeto, Ferreira e Salgado (2007) destacam que o principal benefício da implantação do sistema de gestão da qualidade (certificado ou não) é criação de um sistema de gestão que auxilie na administração e organização dos processos da empresa, e que a certificação do sistema se torna importante quando a contratação da empresa está vinculada à obtenção desta.

Braga e Andery (2012) apontaram que alguns pesquisadores examinaram o impacto desses sistemas nas rotinas de trabalho de escritórios de projeto, mas poucos estudos focaram especificamente a gestão do desenvolvimento dos projetos no âmbito das empresas construtoras contratantes.

Ao estudar uma empresa construtora que possui certificação ISO 9001, também deve-se atentar ao fato de que tão importante quanto as relações e os processos da empresa é 
como isso acontece dentro de cada empreendimento e em suas fases, forma como os dados foram analisados no presente artigo. Melhado (2001) aponta que o sistema da qualidade do empreendimento não resulta da sobreposição entre os eventuais sistemas da qualidade existentes nas empresas participantes. Quando se menciona o sistema de gestão da qualidade dos agentes componentes em um empreendimento, nota-se que há uma preocupação da empresa direcionada à sua organização interna e com os seus clientes diretos. Contudo, ao utilizar-se o empreendimento como referência, a situação se modifica, surgindo deficiências nas interfaces. Essas deficiências devem ser analisadas uma vez que a utilização dos procedimentos de qualidade é feita nos empreendimentos.

A certificação de um sistema de qualidade em uma Construtora pode ser um passo para a melhoria da gestão da qualidade na empresa, no entanto, é necessário verificar se o procedimento é utilizado e seguido conforme planejado. De acordo com OHASHI (2004) apesar de muitas empresas possuírem um sistema de gestão da qualidade com certificação ISO 9001 e/ou outras certificações, muitas delas enfrentam no dia-a-dia dificuldades para garantirem que o sistema esteja "rodando", ou seja, realmente em funcionamento adequado para que possa trazer objetivamente os benefícios de qualidade esperados em seus produtos, processos e em relação aos seus clientes e fornecedores.

Através de análises de estudos de caso, Braga e Andarey (2012) concluíram que, de forma geral, a ISO9001, quando bem implementada nas empresas, confere uma maior confiabilidade no fluxo de informações de projeto. Devido a isso, surge a importância de se avaliar o grau de utilização do procedimento de gestão de projetos e os pontos de atenção dentro deste processo que podem contribuir para uma melhoria futura.

\section{MÉTODOS}

\subsection{Estratégia de Pesquisa}

A estratégia de pesquisa deste artigo contempla um levantamento bibliográfico sobre Qualidade na Gestão do Processo de Projeto seguido de um estudo de caso em uma construtora, no qual foram analisados dados coletados na avaliação da utilização do procedimento de qualidade do departamento de Engenharia e Projetos.

A intenção ao analisar os dados foi verificar a evolução da utilização do procedimento ao longo do tempo, as avaliações por documento e fase do empreendimento analisando quais itens da norma apresentaram maiores problemas e as principais dificuldades encontradas.

\subsection{Caracterização da Construtora e dos Empreendimentos avaliados}

A empresa construtora analisada atua há quarenta anos no mercado nacional com obras de edificações de grande porte do setor privado por encomenda, tendo em seu portfólio maioria de obras comerciais de alto padrão.

A empresa obteve a certificação ISO 9001 em dezembro de 2010, enquanto os empreendimentos foram avaliados no período de julho de 2011 a novembro de 2011, ou seja, iniciou seis meses após o final da implantação do atual sistema de qualidade.

Para a avaliação, foram considerados apenas os empreendimentos que estavam em andamento ao longo de todo período da coleta de dados, os que iniciaram após julho ou finalizaram antes de novembro tiveram seus resultados desconsiderados. Desta forma, esse artigo avaliou doze empreendimentos, sendo cinco em fase de Pré-Construção, 
quando os projetos estão em desenvolvimento e a obra ainda não foi iniciada, e sete em fase de Construção.

Cabe ressaltar que a empresa trabalha da forma estruturada como é hoje em empreendimentos na fase de Pré-Construção desde julho de 2010, enquanto presta serviços de construção desde sua fundação, esse fato também pode contribuir nos resultados encontrados.

Os empreendimentos analisados apresentavam diferentes tipologias, usos, clientes e estão localizados nos estados de São Paulo e Rio de Janeiro. A maioria tem uso comercial ou residencial e tem incorporadoras como cliente principal, sendo que alguns divergem por se tratar de uso hospitalar, hoteleiro ou industrial e por terem empresas privadas ou investidores como cliente.

\subsection{Documentos avaliados e critérios de avaliação}

Os documentos avaliados fazem parte dos processos certificados do Sistema de Qualidade da empresa e estão relacionados com os tópicos do item 7.3. Projeto e Desenvolvimento da norma ISO 9001, conforme mostrado na Tabela 01.

Tabela 1: Relação dos procedimentos com os tópicos da norma ISO 9001

\begin{tabular}{|l|l|}
\hline Procedimentos avaliados & Tópico correspondente da norma \\
\hline Cronograma de Projetos & $7.3 .1 \quad$ Planejamento de Projeto e Desenvolvimento \\
\hline $\begin{array}{l}\text { Registros de Verificação e Análise de } \\
\text { Projetos }\end{array}$ & $\begin{array}{l}7.3 .5 \quad \text { Verificação de Projeto e Desenvolvimento; } \\
7.3 .4 \text { Análise Crítica de Projeto e Desenvolvimento; }\end{array}$ \\
\hline Registros de Validação de Projetos & 7.3 .6 Validação de Projeto e Desenvolvimento; \\
\hline Lista Mestra & 7.3 .7 Controle de Alteração em Projeto e Desenvolvimento. \\
\hline Registros de Alterações de Projetos & 7.3 .7 Controle de Alteração em Projeto e Desenvolvimento. \\
\hline
\end{tabular}

Fonte: Próprio autor.

Para a avaliação eram seguidas quatro gradações sendo elas: Ótimo, Bom, Regular e Ruim, existindo ainda o N/A (Não de aplica) quando ao entender dos avaliadores da Construtora a utilização do documento avaliado não se aplicava ao tipo ou fase do Empreendimento. Os itens com avaliação N/A foram descartados dos resultados. Os critérios dessa avaliação foram aplicados conforme Tabela 02 .

\section{Tabela 2: Critérios de avaliação da utilização dos procedimentos}

\begin{tabular}{|l|l|}
\hline Ótimo & $\begin{array}{l}\text { Controla e possui todos os registros em dia/ Registros atualizados no período conforme } \\
\text { frequência definida }\end{array}$ \\
\hline Bom & $\begin{array}{l}\text { Controla e possui a maioria dos registros em dia/ Registros atualizados no período } \\
\text { anterior ou no período sem a frequência correta. }\end{array}$ \\
\hline Regular & $\begin{array}{l}\text { Controla e possui alguns registros em dia/ Sem ação entre o período anterior e o período } \\
\text { atual }\end{array}$ \\
\hline Ruim & Não controla/ Sem ação por mais de 2 períodos consecutivos \\
\hline N/A & Não se aplica ao Empreendimento \\
\hline
\end{tabular}

Fonte: Próprio autor. 


\subsection{Processo de avaliação}

As avaliações foram realizadas por arquitetos do departamento de Engenharia e Projetos da empresa que não estavam envolvidos com nenhum dos empreendimentos avaliados e o processo consistiu em analisar virtualmente os documentos ao final de cada mês e registrar o resultado dessa análise na ferramenta definida para o registro das avaliações. Como a avaliação era feita a distância, ou seja, não havia contato direto com a equipe do Empreendimento, só eram válidos os registros que estavam dentro do sistema de informação da empresa.

A ferramenta utilizada para o registro era uma planilha na qual para cada documento avaliado era dada uma nota de acordo com os critérios apresentados no item 4.3. e havia um espaço para descrever quais foram os problemas encontrados na avaliação.

A avaliação dos documentos era feita baseada no que está descrito no Procedimento de Gestão do Processo de Projeto da empresa e no Plano de Qualidade do Empreendimento que descrevia como aquele empreendimento controlaria seus registros, frequência de atualização, etc. O Procedimento é único para toda empresa, enquanto o Plano de Qualidade do Empreendimento é feito para cada um, sempre seguindo os procedimentos do sistema de Qualidade da Construtora.

É importante ressaltar que durante a coleta de dados a empresa passou por uma Auditoria Externa, que aconteceu no mês de outubro, essa informação pode ser importante na análise da evolução ao longo do tempo e do impacto de uma auditoria na utilização dos procedimentos de qualidade.

Os resultados da avaliação eram divulgados todo mês pela gerência do departamento de Engenharia e Projetos para a equipe responsável pela gestão do processo de projeto nos empreendimentos e para seus superiores (gerentes e diretores). Além da avaliação qualitativa, a análise também trazia comentários demonstrando quais eram os problemas apresentados para que a equipe pudesse a partir disso melhorar o desempenho para o próximo mês.

Como forma de incentivo ao cumprimento do Procedimento, o desempenho nas avaliações foi atrelado às metas dos profissionais responsáveis diretamente pela gestão do processo.

\section{RESULTADOS E DISCUSSÕES}

\subsection{Evolução dos resultados ao longo do tempo}

Com os dados obtidos, o primeiro resultado extraído foi a evolução da avaliação dos empreendimentos ao longo do tempo, os empreendimentos foram separados pela fase em que se encontravam.

Nas Figuras 01 e 02 está demonstrado o gráfico que representa a evolução. Nos empreendimentos de Pré-Construção foi verificado que o grau de utilização no primeiro mês de avaliação era baixo, tendo somente $40 \%$ dos registros avaliados como "Bom" ou "Ótimo", já na avaliação das Obras, o cenário inicial se mostrou diferente e $88 \%$ dos registros foram bem avaliados

No entanto, ao analisar a evolução ao longo do tempo, é clara a melhoria das avaliações nos empreendimentos de Pré-Construção que tiveram curva ascendente, iniciando nos $40 \%$ e atingindo $92 \%$ de procedimentos avaliados como "Ótimo" e "Bom" no último mês de avaliação. Nas Obras a avaliação se manteve relativamente constante, variando 12 pontos percentuais e com uma média de $89 \%$ tendo um excepcional desempenho no mês de Outubro quando 97\% dos registros foram avaliados como "Ótimo" ou "Bom", o 
desempenho acima do normal pode ser atribuído a realização de uma Auditoria Externa no período, conforme relatado no item 4.4. Apesar de não manter o desempenho do período anterior, no último mês a avaliação se manteve positiva, tendo $90 \%$ dos procedimentos bem avaliados.

Figura 1: Evolução da avaliação dos empreendimentos em fase de Pré-Construção

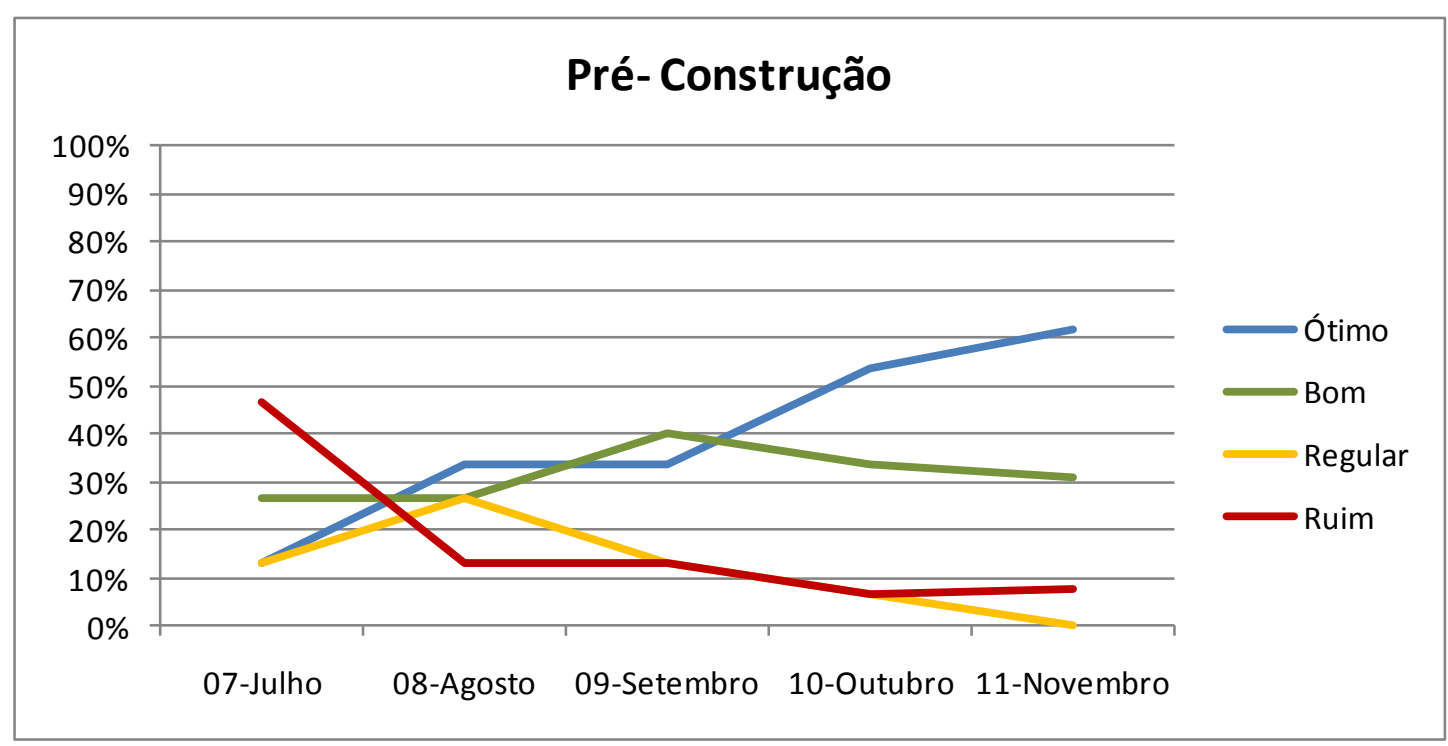

Fonte: Próprio autor.

Figura 2: Evolução da avaliação dos empreendimentos em fase de Obra

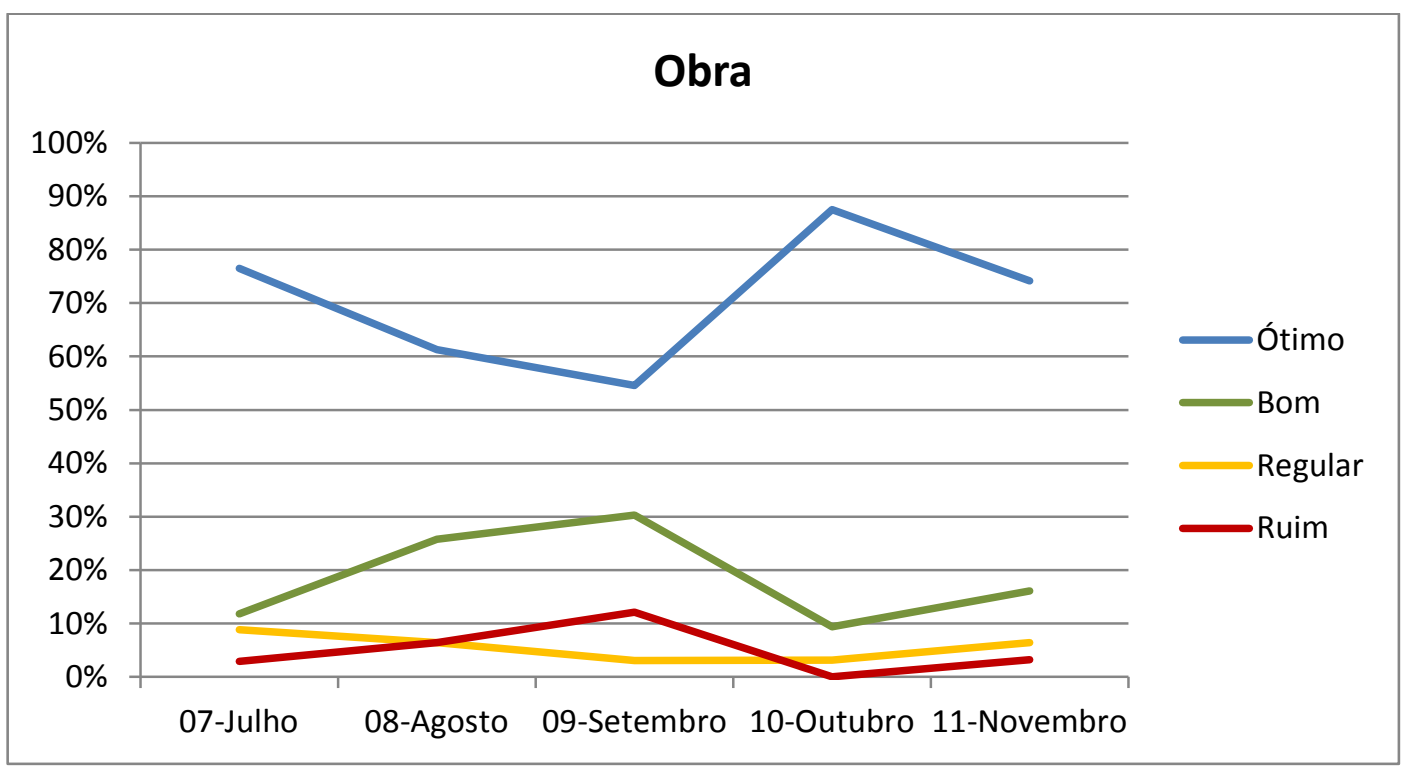

Fonte: Próprio autor.

O bom desempenho das Obras nas avaliações pode ser atribuído ao fato de que a empresa tem como seu negócio principal os serviços de Construção desde sua fundação, esse fato implica tanto na metodologia consolidada de gestão do processo de projeto em obras, quanto no perfil dos profissionais que atuam como líderes desse processo. Além disso, foram encontrados outros dois fatores que podem ter contribuído: a divulgação dos resultados mensalmente à equipe e à gerencia e diretoria e o fato de que $\mathrm{o}$ desempenho dos empreendimentos estava atrelado às metas dos profissionais, incentivando os responsáveis pela gestão a cumprir os procedimentos.

Nas Pré-Construções ficou claro o esforço para melhorar a utilização e a qualidade dos registros que ao final já havia atingido avaliação similar às Obras. $\mathrm{O}$ fato de a empresa 
prestar esse tipo de serviço de forma estruturada há menos de um ano antes do início das avaliações contribuiu para que no início a avaliação fosse insatisfatória. Como fatores que podem ter influenciado a melhoria ao longo do tempo pode-se destacar alguns similares aos apresentados nas Obras como divulgação dos resultados e conexão dos resultados com as metas dos funcionários. Além disso, a realização de treinamentos da equipe, bem como a melhor estruturação do departamento para atender especificamente esse tipo de empreendimento também influenciou a melhoria.

\subsection{Avaliação qualitativa dos registros e dificuldades encontradas}

A segunda análise realizada consistiu em avaliar por tipo de registro qual foi o desempenho apresentado, desconsiderando o fator tempo levantado no item anterior, porém mantendo a separação por fase do Empreendimento, conforme mostrado na Figura 03.

Nesta análise, verificou- se que na fase de Pré-Construção, o tipo de registro que obteve pior avaliação foi o de Verificação e Análise de Projetos, tendo 54\% dos registros avaliados como "Regular" ou "Ruim". Novamente, o fato de a empresa ter se estruturado recentemente para oferecer os serviços ao longo da etapa de Pré-Construção contribuiu para esse resultado.

No entanto, as avaliações dos Cronogramas na fase de Pré-Construção foram boas, tendo somente $17 \%$ dos registros avaliados como "Regular" e nenhum como "Ruim". Esse fato pode mostrar que, na fase que antecede a obra, a empresa estava mais focada no planejamento e controle da gestão do processo de projeto.

$\mathrm{Na}$ análise dos registros de Obras, destaca-se dois tipos de registro que obtiveram pior avaliação: Registro de Alterações de projetos, com 32\% e Cronograma de Projetos com $24 \%$ de avaliações "Regular" ou "Ruim".

O fato de os registros de alterações terem $32 \%$ de suas avaliações abaixo do desejável e de, ao mesmo tempo, os registros de Lista Mestra apresentarem apenas 3\% de avaliações regulares e nenhuma ruim mostra que a nas Obras a empresa cumpriu bem o controle documental do que pede o item 7.3.7 da norma ISO 9001, no entanto pode ter apresentado algumas dificuldades no cumprimento das ações de análise dessas alterações.

O fato de os Cronogramas de Projetos serem pior avaliados na fase de Obra do que na fase de Pré-Construção, apesar de no geral o desempenho das Obras ter apresentado melhores resultados, pode mostrar que durante a construção a empresa diminui o foco no planejamento da gestão do processo de projeto dando maior ênfase as análises críticas e controle de lista mestra. 


\section{Figura 3: Avaliação qualitativa dos registros}

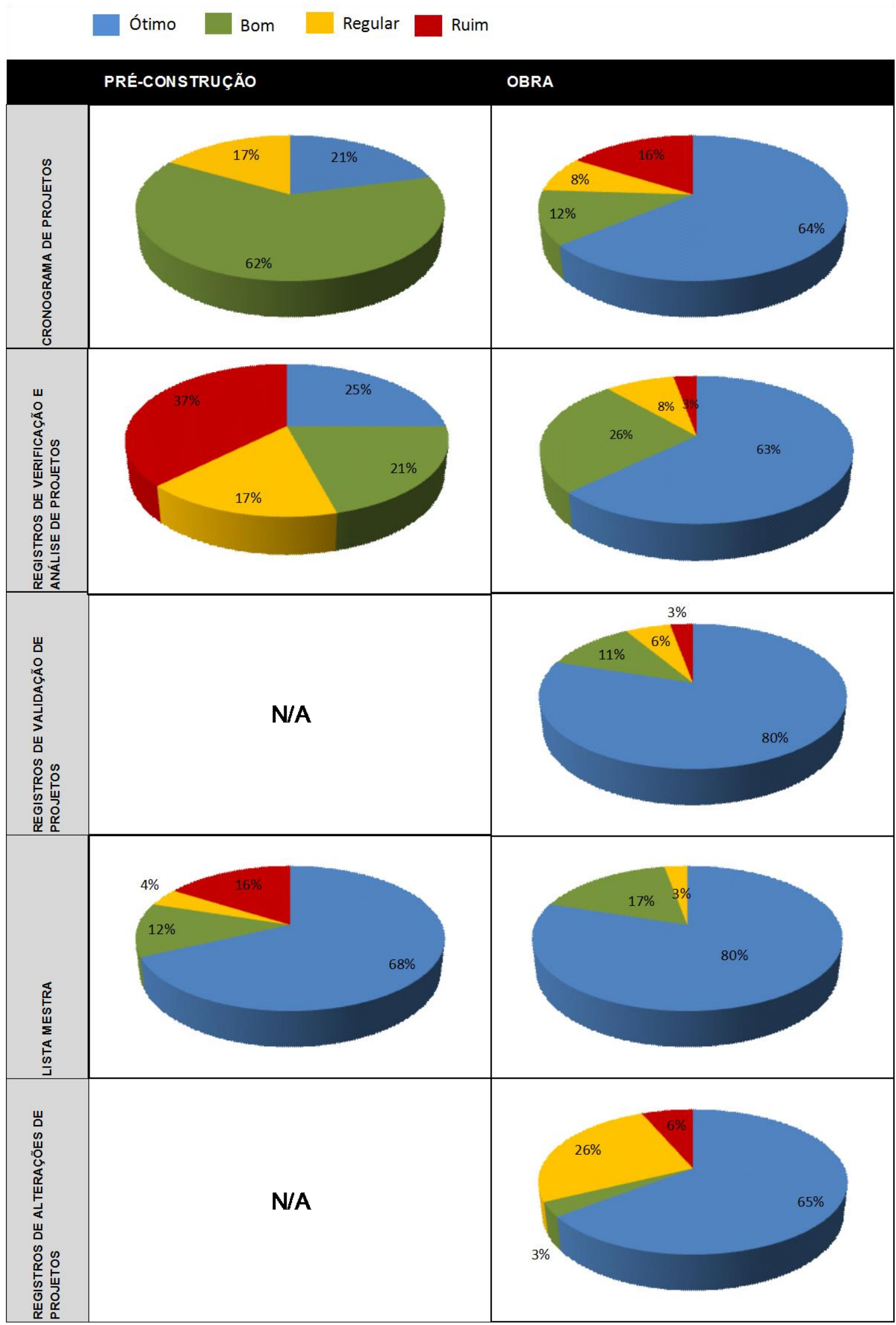

Fonte: Próprio autor.

Os principais problemas registrados na coleta de dados foram compilados na Tabela 03 , mostrando o motivo das avaliações ruins ou regulares em cada tipo de registro. 
Tabela 3: Principais problemas encontrados

\begin{tabular}{|c|c|c|}
\hline & Pré-Construção & Obra \\
\hline Cronograma & $\begin{array}{l}\text { - } \quad \text { Falta de atualização e } \\
\text { acompanhamento do Cronograma }\end{array}$ & $\begin{array}{l}\text { - } \quad \text { Falta de atualização e } \\
\text { acompanhamento do Cronograma }\end{array}$ \\
\hline $\begin{array}{l}\text { Registros de } \\
\text { Verificação e } \\
\text { Análise de } \\
\text { Projetos }\end{array}$ & $\begin{array}{l}\text { • } \\
\text { recebidos. } \\
\bullet \quad \text { Falhas na utilização da } \\
\text { ferramenta para registro } \\
\text { - } \quad \text { Falta de planejamento e } \\
\text { sistematização das análises. } \\
\end{array}$ & $\begin{array}{l}\text { - } \quad \text { Demora na análise dos projetos } \\
\text { recebidos. } \\
\bullet \quad \text { Falta de planejamento e } \\
\text { sistematização das análises. }\end{array}$ \\
\hline $\begin{array}{l}\text { Registros de } \\
\text { Validação de } \\
\text { Projetos }\end{array}$ & N/A & $\begin{array}{l}\text { Problemas quanto à compreensão } \\
\text { do conceito de Validação de Projetos. }\end{array}$ \\
\hline Lista Mestra & Não utilização do controle & - $\quad$ Falta de atualização \\
\hline $\begin{array}{l}\text { Registros de } \\
\text { Alterações de } \\
\text { Projetos }\end{array}$ & N/A & $\begin{array}{l}\text { - Ausência de registro e controle } \\
\text { das alterações de projetos ocorridas } \\
\text { durante a obra }\end{array}$ \\
\hline
\end{tabular}

Fonte: Próprio autor.

\section{CONCLUSÕES}

Com a pesquisa realizada pode-se concluir alguns pontos quanto à utilização do procedimento de gestão do processo de projeto e suas principais problemáticas na empresa Construtora estudada:

O fato de a empresa trabalhar com Obras como seu negócio principal contribuiu para que em empreendimentos nesta fase, inicialmente a aderência fosse maior;

Incentivos da gerencia e diretoria podem ter auxiliado no bom desempenho dos empreendimentos quanto ao cumprimento do procedimento;

A boa estruturação do departamento responsável pela gestão do processo de projeto pode ter influenciado na melhor utilização do procedimento;

No estudo de caso analisado, na fase de Pré-Construção mostrou-se a necessidade de aprimorar e agilizar as atividades e registros referentes a verificação e análise crítica de projetos (itens 7.3.4 e 7.3.5 ISO 9001);

No estudo de caso analisado, na fase de Obra, mostrou-se a necessidade de aprimorar e agilizar as atividades e registros referentes a planejamento e controle de alterações de projetos (item7.3.1 e 7.3.7 ISO 9001);

Para trabalhos futuros sugere-se realizar a coleta de dados em outras empresas construtoras, além de avaliar também as ferramentas utilizadas e o impacto disso na boa ou má utilização do procedimento. 


\section{BIBLIOGRAFIA}

ABNT, NBR ISO 9001:2008, Sistemas de gestão da qualidade - Requisitos, Rio de Janeiro, ABNT - Associação Brasileira de Normas Técnicas, 2008.

BRAGA, R.E., ANDERY, P.R.P. Influência dos sistemas de gestão da qualidade no processo de projeto de empresas construtoras. Construindo, Belo Horizonte, v. 5, n. 2, Jun/Dez. 2012.

FERREIRA, C. e SALGADO, M. Impacto da ISSO 9001:2000 nos aspectos gerenciais dos escritórios de arquitetura: estudo de caso em empresas certificadas. Revista Gestão \& Tecnologia de Projetos, vol. 2, no.1, 2007

MELHADO, S.B. Gestão, cooperação e integração para um novo modelo voltado a qualidade do processo de projeto na construção de edifícios. 2001. Tese (Livredocência) - Escola Politécnica, Universidade de São Paulo, São Paulo.

OHASHI, E.A.M, MELHADO S.B. A importância dos indicadores de desempenho nas empresas construtoras e incorporadoras com certificação ISO 9001:2000. 2004. ENTAC, São Paulo.

PICCHI, F.A. Sistemas da qualidade: uso em empresas de construção de edifícios. São Paulo, 1993a. 426p. Tese (Doutorado) - Escola Politécnica, Universidade de São Paulo.

PROJECT MANAGEMENT INSTITUTE - PMI. Um Guia Do Conhecimento Em Gerenciamento De Projetos (Guia PMBOK®). 5ed.: Project Management Institute, 2014. 589p. 